\title{
XLI. The internal work of the wind
}

\section{S. P. Langley}

To cite this article: S. P. Langley (1894) XLI. The internal work of the wind, Philosophical Magazine Series 5, 37:228, 425-448, DOI: 10.1080/14786449408620570

To link to this article: http://dx.doi.org/10.1080/14786449408620570

$$
\text { 曲 Published online: } 08 \text { May } 2009 .
$$

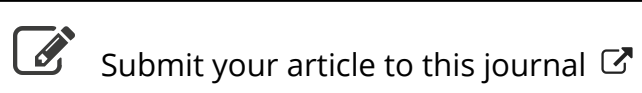

\footnotetext{
Џll Article views: 2
}

Q View related articles $₫$

4 Citing articles: 1 View citing articles 
THE

\title{
LONDON, EDINBURGH, aND DUBLIN \\ PHILOSOPHICAL MAGAZINE
}

\author{
AND \\ JOURNAL OF SCIENCE.
}

[FIFTH SERIES.]

MA $Y 1894$.

XLI. The Internal Work of the Wind.

By S. P. LANGLEY*.

[Plates V.-IX.]

PART I.-Introductory.

$T^{\mathrm{T}}$ has long been observed that certain species of birds 1 maintain themselves indefinitely in the air by "soaring," without any flapping of the wing or any motion other than a slight rocking of the body; and this, although the body in question is many hundred times denser than the air in which it seems to float with an undulating movement, as on the waves of an invisible stream.

No satisfactory mechanical explanation of this anomaly has been given, and none would be offered in this connexion by the writer, were he not satisfied that it involves much more than an ornithological problem, and that it points to novel conclusions of mechanical and utilitarian importance. They are paradoxical at first sight, since they imply that under certain specified conditions very heavy bodies entirely detached from the earth, immersed in, and free to move in, the air, can be sustained there indefinitely, without any expenditure of energy from within.

These bodies may be entirely of mechanical construction,

* A paper read (by title only) to the National Academy of Sciences, in April 1893, and subsequently (in full) at the Aeronautical Congress, at Chicago, in August, 1893. Communicated by the Author, to whom we are likewise indebted for cliches of the plates.

Phil. Mag. S. 5. Vol. 37. No. 228. May 1894. 2 Gr 
as will be seen later, but for the present we will continue to consider the character of the invisible support of the soaring bird, and to study its motions, though only as a pregnant instance offered by nature to show that a rational solution of the mechanical problem is possible.

Recurring, then, to the illustration just referred to, we may observe that the flow of an ordinary river would afford no explanation of the fact that nearly inert creatures, while free to move, although greatly denser than the fluid, yet float upon it; which is what we actually behold in the aerial stream, since the writer, like others, has satisfied himself by repeated observation that the soaring vultures and other birds appear as if sustained by some invisible support, in the strenm of air, sometimes for at least a considerable fraction of an hour. It is frequently suggested by those who know these facts only from books, that there must be some quivering of the wings, so rapid as to escape observation. Those who do know them from observation are aware that it is absolutely certain that nothing of the kind takes place, and that the birds sustain themselves on pinions which are quite rigid and motionless, except for a rocking or balancing movement involving little energy.

The writer desires to acknowledge his indebtedness to that most conscientious observer, M. Mouillard *, who has described these actions of the soaring birds with incomparable vividness and minuteness, and who asserts, that they, under certain circumstances, withont flapping their wings, rise and actually advance against the wind.

To the writer, who has himself been attracted from his earliest years to the mystery which has surrounded this action of the soaring bird, it has been a subject of continual surprise that it has attracted so little attention from physicists. That nearly inert bodies, weighing from 5 to 10, and even more, pounds, and many hundred times denser than the air, should be visibly suspended in it above our heads, sometimes for hours at a time, and without falling,- - this, it might seem, is, without misuse of language, to be called a physical miracle; and yet the fact that those whose province it is to investigate nature have hitherto seldom thought it deserving attention is perhaps the greater wonder.

This indifference may be in some measure explained by the fact that the largest and best soarers are of the vulture kind, and that their most striking evolutions are not to be seen in those regions of the Northern Temperate Zone where the majority of those whose training fits them to study the sub-

* L. P. Mouillard, L'Empire de l'Air, Paris : G. Masson. 
ject are found. Even in Washington, however, where the writer at present resides, scores of great birds may be seen at times in the air together, gliding with and against the wind, and ascending higher at pleasure, on nearly motionless wings. "Those who have not seen it," says M. Mouillard, "when they are told of this ascension without the expenditure of energy, are always ready to say, "but there must have been movements, though you did not see them;" "and in fact," he adds, "the casual witness of a single instance, himself, on reflection, feels almost a doubt as to the evidence of his senses, when they testify to things so extraordinary."

Quite agreeing with this, the writer will not attempt any general description of his own observations, but as an illustration of what can sometimes be seen, will give a single one, to whose exactness he can personally witness. The common "Turkey Buzzard" (Cathartes aura) is so plentiful around the environs of Washington that there is rarely a time when some of them may not be seen in the sky, gliding in curves over some attractive point, or, more rarely, moving in nearly straight lines on rigid wings, if there be a moderate wind. On the only occasion when the motion of one near at hand could be studied in a very high wind, the author was crossing the long "Aqueduct Bridge" over the Potomac, in an unusually violent November gale, the velocity of the wind being probably over 35 miles an hour. About one third of the distance from the right bank of the river, and immediately over the right parapet of the bridge, at a height of not over 20 yards, was one of these buzzards, which, for some object which was not evident, chose to keep over this spot, where the gale, undisturbed by any surface irregularities, swept directly up the river with unchecked violence. In this aerial torrent, and apparently indifferent to it, the bird hung, gliding in the usual manner of its species, round and round, in a small oval curve, whose major axis (which seemed toward the wind) was not longer than twice its height from the water. The bird was therefore at all times in close view. It swung around repeatedly, rising and falling slightly in its course, while keeping, as a whole, on one level, and over the same place, moving with a slight swaying, both in front and lateral direction, but in such an effortless way as suggested a lazy yielding of itself to the rocking of some invisible wave.

It may be asserted that there was not only no flap of the wing, but not the quiver of a wing-feather visible to the closest scrutiny, during the considerable time the bird was under observation, and during which the gale continued. A record of this time was not kept, but it at any rate lasted until $2 \mathrm{G} 2$ 
the writer, chilled by the cold blast, gave up watching and moved away, leaving the bird still floating about, at the same height in the torrent of air, in nearly the same circle, and with the same aspect of indolent repose.

If the wind is such a body as it is commonly supposed to be, it is absolutely impossible that this sustention could have taken place in a horizontal current any more than in a calm, and yet that the ability to soar is, in some way, connected with the presence of the wind, became to the writer as certain as any fact of observation could be, and at first the difficulty of reconciling such facts (to him undoubted) with accepted laws of motion seemed quite insuperable.

Light came to him through one of those accidents which are commonly found to occur when the mind is intent on a particular subject, and looking everywhere for a clue to its solution.

In 1887, while engaged with the "whirling-table" in the open air at the Allegheny Observatory, he had chosen a quiet afternoon for certain experiments, but in the absence of the entire calm, which is almost never realized, had placed one of the very small and light anemometers made for hospital use in the open air, with the object of determining and allowing for the velocity of what feeble breeze existed. His attention was called to the extreme irregularity of this register, and he assumed at first that the day was more unfavourable than he had supposed. Subsequent observations, however, showed that when the anemometer was sufficiently light and devoid of inertia, the register always showed great irregularity, especially when its movements were noted, not from minute to minute, but from second to second.

His attention once aroused to these anomalies, he was led to reflect upon their extraordinary importance in a possible mechanical application. He then designed certain special apparatus hereafter described, and made observations with it which showed that "wind" in general was not what it is commonly assumed to be-that is, air put in motion with an approximately uniform velocity in the same strata; but that, considered in the narrowest practical sections, wind was always not only not approximately uniform, but variable and irregular in its movements beyond anything which had been anticipated, so that it seemed probable that the very smallest part observable could not be treated as approximately homogeneous, but that even here there was an internal motion to be considered, distinct both from that of the whole body and from its immediate surroundings. It seemed to the writer to follow as a necessary consequence, that there night be a 
potentiality of what may be called "internal work" * in the wind.

On further study, it seemed to him that this internal work might conceivably be so utilized as to furnish a power which should not only keep an inert body from falling, but cause it to rise, and that while this power was the probable cause of the action of the soaring bird, it might be possible through its means to cause any suitably disposed body, animate or inanimate, wholly immersed in the wind and wholly free to move, to advance against the direction of the wind itself. By this it is not meant that the writer then devised means for doing this, but that he then attained the conviction both that such an action involved no contradiction of the laws of motion, and that it was mechanically possible (however difficult it might be to realize the exact mechanism by which this might be accomplished).

It will be observed that in what has preceded it is intimated that the difficulties in the way of regarding this even in the light of a theoretical possibility may have proceeded, with others as with the writer, not from erroneous reasoning, but from an error, in the premisses, entering insidiously in the form of the tacit assumption made by nearly all writers, that the word "wind" means something so simple, so readily intelligible, and so commonly understood, as to require no special definition; while, nevertheless, the observations which are presently to be given show that it is, on the contrary, to be considered as a generic name for a series of infinitely complex and little-known phenomena.

Without determining here whether any mechanism can be actually devised which shall draw from the wind the power to cause a body wholly immersed in it to go against the wind, the reader's consideration is now first invited to the evidence that there is no contradiction to the known laws of motion, and at any rate no theoretical impossibility in the conception of such a mechanism, if it is admitted that the wind is not what it has been ordinarily taken to be, but what the following observations show that it is.

What immediately follows is an account of evidence of the complex nature of the "wind," of its internal movements, of

* Since the term "internal work" is often used in thermodynamics to signify molecular action, it may be well to observe that it here refers not to molecular movements, but to pulsations of sensible magnitude, always existing in the wind, as will be shown later, and whose extent and extraordinary possible mechanical importance it is the object of this research to illustrate. The term is so significant of the author's meaning; that be permits bimself the use of it here, in spite of the possible ambiguity. 
the resulting potentiality of this internal work, and of attempts which the writer has made to determine quantitatively its amount by the use of special apparatus, recording the changes which go on (so to speak) within the wind in very brief intervals. These results may, it is hoped, be of interest to meteorologists, but they are given here with special reference to their important bearing on the future of what the writer has ventured to call the science of Aerodromics*.

The observations which are first given were made in $\mathbf{1 8 8 7}$ at Allegheny, and are supplemented by others made at Washington in the present year $\dagger$.

What has just been said about their possible importance will perhaps seem justified, if it is remarked (in anticipation of what follows later) that the result of the present discussion implies not only the theoretical, but the mechanical possibility, that a heavy body wholly immersed in the air, and sustained by it, may without the ordinary use of wind, or sail, or steam, and without the expenditure of any power except such as may be derived from the ordinary winds, make an aerial voyage in any direction, whose length is only limited by the occurrence of a calm. A ship is able to go against a head wind by the force of that wind, owing to the fact that it is partly immersed in the water which reacts on the keel, but it is here asserted that (contrary to usual opinion and in opposition to what at first may seem the teachings of physical science) it is not impossible that a heavy and nearly inert body wholly immersed in the air can be made to do this.

The observations on which the writer's belief in this mechanical possibility are founded will now be given.

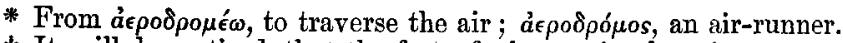

+ It will be noticed that the fact of observation here is not so much the movement of currents, such as the writer has since learned was suggested by Lord Rayleigh so long ago as 1883, still less of the movement of distinct currents at a considerable distance above the earth's surface, but of what must be rather called the effect of the irregularities and pulsations of any ordinary wind, within the immediate field of examination, however narrow.

See the instructive article by Lord Rayleigh in 'Nature,' April 5, 1883. Lord Rayleigh remarks that continued soaring implies "(1) that the course is not horizontal, (2) that the wind is not horizontal, or (3) that the wind is not uniform." "It is probable," he says, " that the truth is usually represented by (1) or (2) ; but the question I wish to raise is whether the cause suggested by (:) may not sometimes come into operation." 
PART II.-Experiments with the use of special apparatus.

In the ordinary uses of the anemometer (let us suppose it to be a Robinson's anemometer, for illustration) the registry is seldom taken as often as once a minute; thus, in the ordinary practice of the United States Weather Bureau, the registration is made at the completion of the passage of each mile of wind. If there be very rapid fluctuations of the wind, it is obviously desirable, in order to detect them, to observe the instrument at very brief intervals, $e . g$. at least every second, instead of every minnte or every hour, and it is equally obvious that in order to take up and indicate the changes which occur in these brief intervals, the instrument should have as little inertia as possible, its momentum tending to falsify the facts, by rendering the record more uniform than would otherwise be the case.

In 1887 I made use of the only apparatus at commandan ordinary small Robinson's anemometer, having cups 3 inches ( 7.5 centim.) in diameter, the centres of the cups being

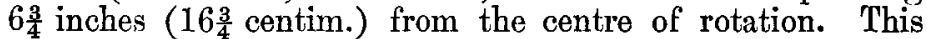
was placed at the top of a mast 53 feet (16.2 metres) in height, which was planted in the grounds of the Allegheny Observatory, on the flat summit of a hill which rises nearly 400 feet (122 metres) above the valley of the Ohio River. It was, accordingly, in a situation exceptionally free from those irregularities of the wind which are introduced by the presence of trees and of houses, or of inequalities of surface.

Every twenty-fifth revolution of the cups was registered by closing an electric circuit, and the registry was made on the chronograph of the Observatory by a suitable electric connexion, and these chronograph sheets were measured and the results tabulated. A portion of the record obtained on July 16,1887 , is given on Plate $V$., the abscissæ representing time, and the ordinates wind velocities. The observed points represent the wind's velocities as computed from the intervals between each successive electrical contact, as measured on the chronograph sheets, and for convenience in following the succession of observed points they are here joined by straight lines, though it is hardly necessary to remark that the change in velocity is in fact, though quite sharp, yet not in general discontinuous, and the straight lines here used for convenience do not imply that the rate of change of velocity is uniform.

The wind velocities during this period of observation ranged from about 10 to 25 miles an hour, and the frequency of measurement was every 7 to 17 seconds. If, on the one hand, 
Phil. Mag. S. 5. Vol. 37. Pl, V.

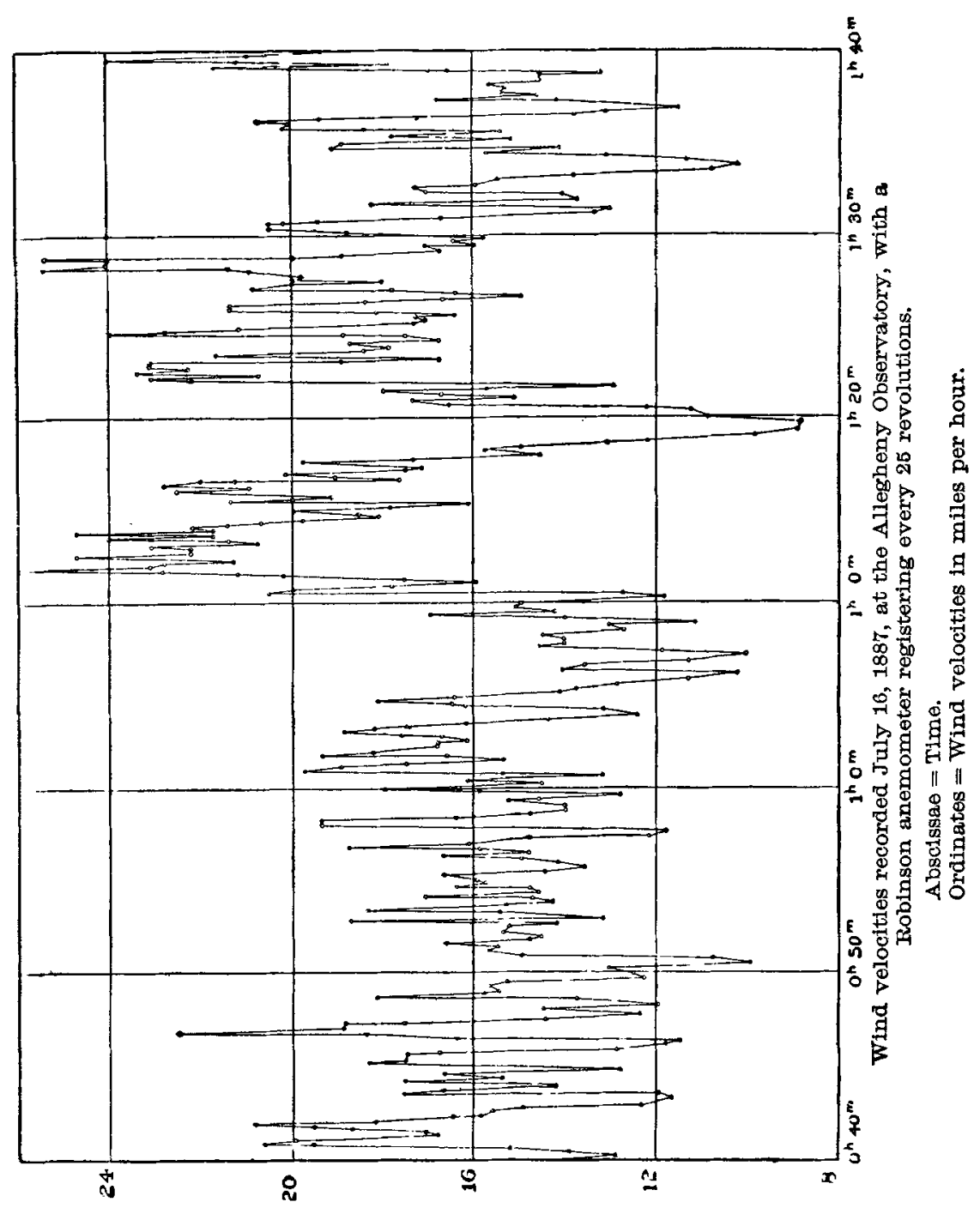


owing to the weight and inertia of the anemometer, this is far from doing justice to the actual irregularities of the wind, on the other it equally shows that the wind was far from being a body of even approximate uniformity of motion, and that even when considered in quite small sections, the motion was found to be irregular almost beyond conception-certainly beyond anticipation; for this record is not selected to represent an extraordinary breeze, but the normal movement of an ordinary one.

By an application of these facts, to be presented later, I then reached by these experiments the conclusion that it was theoretically possible to cause a heavy body wholly immersed in the wind to be driven in the opposite direction, e.g. to move east while the wind was blowing west, without the use of any power other than that which the wind itself furnished, and this even by the use of plane surfaces, and without taking advantage of the more advantageous properties of curved ones.

This power, I further already believed myself warranted by these experiments in saying, could be obtained by the movements of the air in the horizontal plane alone, even without the utilization of currents having an upward trend. But I was obliged to turn to other occupations, and did not resume these interesting observations until the year 1893 .

Although the anemometer used at Allegheny served to illustrate the essential fact of the rapid and continuous fluctuations of even the ordinary and comparatively uniform wind, yet owing to the inertia of the arms and cups, which tended to equalize the rate (the moment of inertia was approximately $40,000 \mathrm{gr} . \mathrm{cm}^{2}$ ), and to the fact that the record was only made at every twenty-fifth revolution, the internal changes in the horizontal component of the wind's motion, thus representing its potential work, were not adequately recorded.

In January 1893 I resumed these observations at Washington with apparatus with which 1 sought to remedy these defects, using as a station the roof of the north tower of the Smithsonian Institution building, the top of the parapet being 142 feet (43.3 metres) above the ground, and the anemometers, which were located above the parapet, being 153 feet (46.7 metres) above the ground. I placed them in charge of Mr. George E. Curtis, with instructions to take observations under the conditions of light, moderate, and high winds. The apparatus used was, first, a Weather Bureau Robinson anemometer of standard size, with aluminium cups. Diameter to centre of cups $34 \mathrm{~cm}$; diameter of cups $10 \cdot 16 \mathrm{~cm}$.; weight of arms and cups 241 grams; approximate moment of inertia $40,710 \mathrm{gr} . \mathrm{cm}^{2}$ 
A second instrument was a very light anemometer, having paper cups, of standard pattern and diameter, the weight of arms and cups being only 74 grams, and its moment of inertia 8604 gr. $\mathrm{cm}^{2}$

With this instrument a number of observations were taken, when it was lost by being blown away in a gale. It was succeeded in its use by one of my own construction, which was considerably lighter. This was also blown away. I afterwards employed one of the same size as the standard pattern, weighing 48 grams, having a moment of inertia of $11,940 \mathrm{gr} . \mathrm{cm} .{ }^{2}$; and, finally, I constructed one of half the diameter of the standard pattern, employing cones instead of hemispheres, weighing 5 grams, and having a moment of inertia of but 300 gr. cm.

In the especially light instruments the electric record was made at every half revolution, on an ordinary astronomical chronograph, placed upon the floor of the tower, connected with the anemometer by an electric circuit. Observations were made on January 14, 1893, during a lighit wind having a velocity of from 9 to 17 miles an hour; on January 25 and 26 during a moderate wind, having a velocity of from 16 to 28 miles an hour ; and on February 4 and 7, during a moderate and bigh wind ranging from 14 to 36 miles an hour. Portions of these observations are given on Plates VI., VII., and VIII. A short portion of the record obtained with the standard Weather Burean anemometer during a high north-west wind is given on Plate IX.

A prominent feature presented by these diagrams is that the higher the absolute velocity of the wind, the greater the relative fluctuations which occur in it. In a high wind the air moves in a tumultuous mass, the relocity being at one moment perhaps 40 miles an hour, then diminishing to an almost instantaneous calm, and then resuming *

The fact that an absolute local calm can momentarily occur during the prevalence of a high wind was vividly impressed upon me during the observations of February 4, when, chancing to look up to the light anemometer, which was revolving so rapidly that the cups were not separately distinguishable, I saw them completely stop for an instant, and then resume their previous high speed of rotation, the whole within the fraction of a second. This confirmed the suspicion that the chronographic record, even of a specially light anemometer, at most but imperfectly notes the sharpness of these

* An example of a very rapid change may be seen on Plate VIII. at 12,23 P.Mr, 
Phil. Mag. S. 5. Vol. 37. Pl. VI.
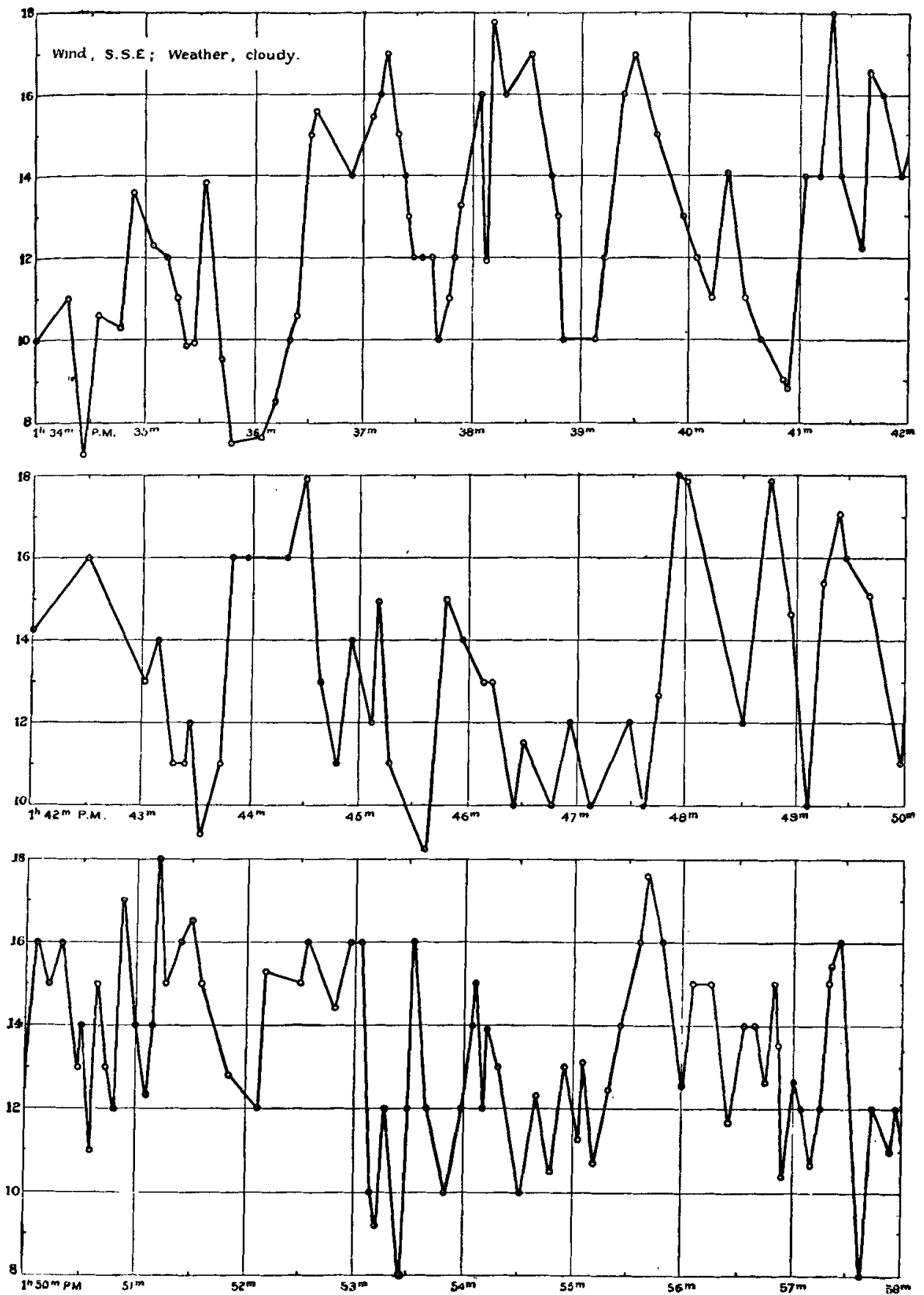

Wind velocities recorded January 14, 1893, at the Smithsonian Institutiou, with a light Robinson anemomoter (paper cups) registering every revolution. 
Phil. Mag. S. 5. Vol. 37. Pl. VII.

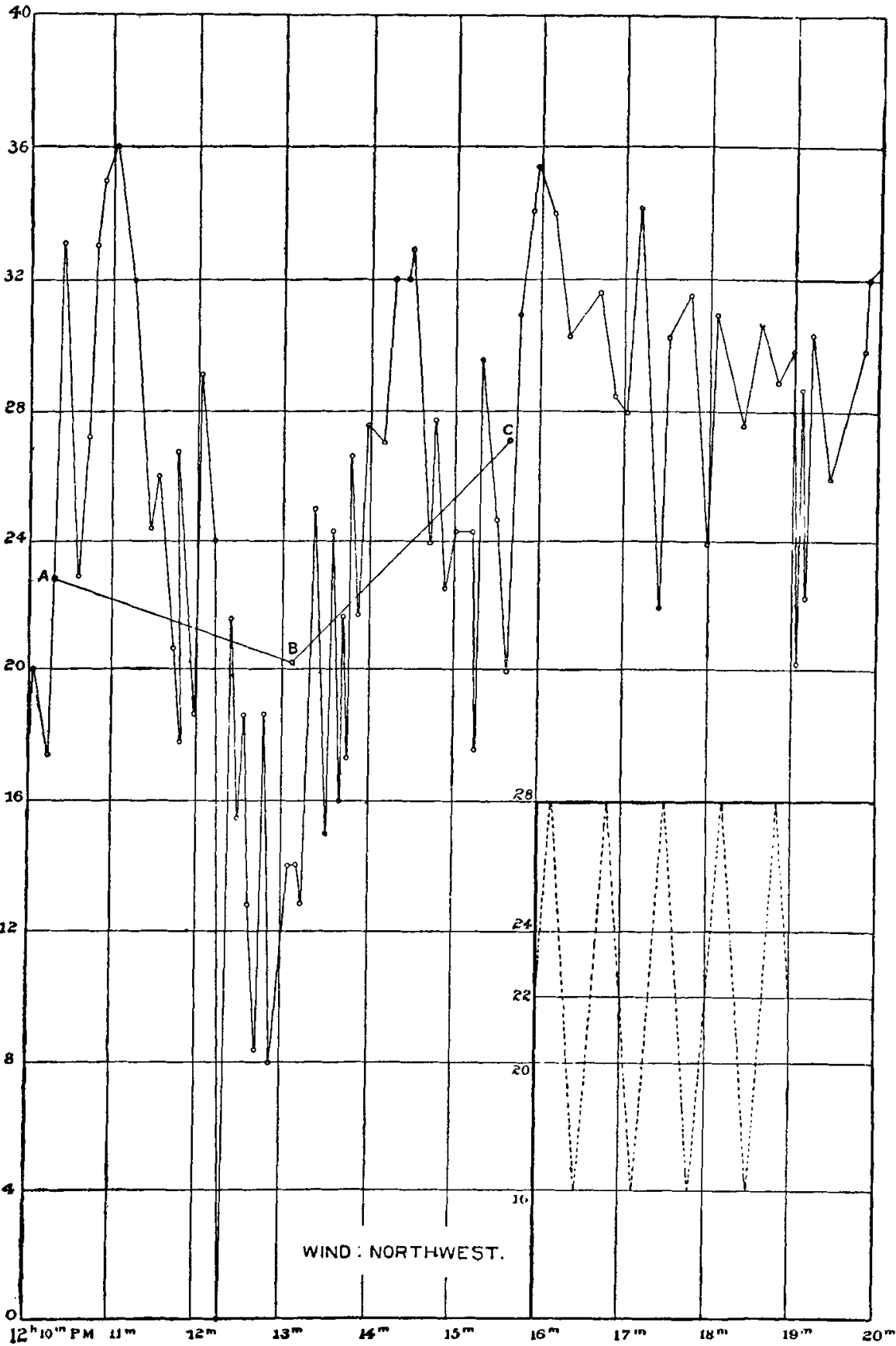

Wind velocities recorded February 4, 1893, at the Smithsonian Institution, with a light Robinson anemometer (paper cups) registering every revolution. 

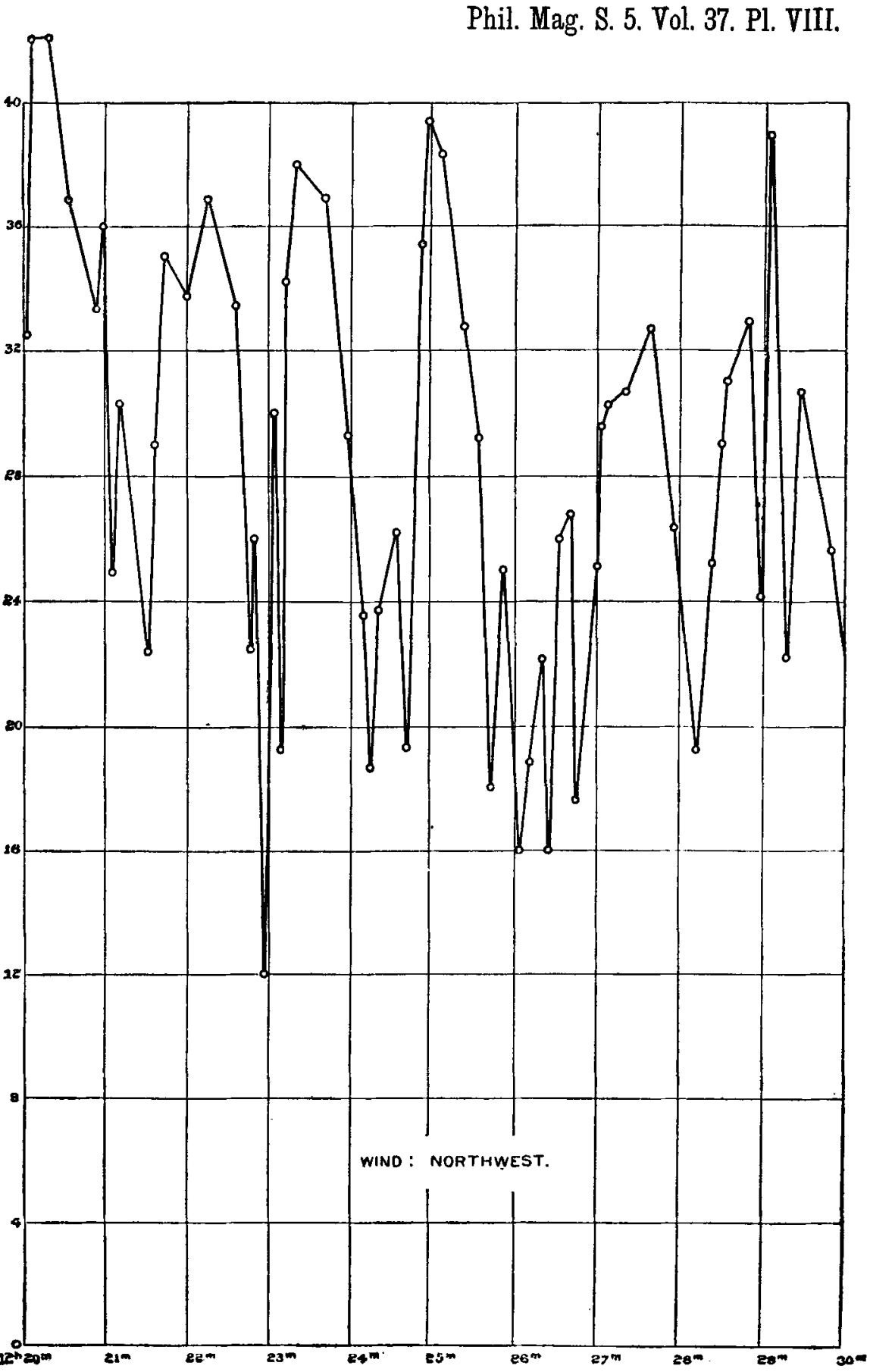

Wind velocities recorded Fobruary 4, 1893, at the Smithsonian Institution, with a light Robinson anemometer (paper cups) registering every revolution. Abscissa $\theta=$ Time

Ordinates $=$ Wind velocities in miles per hour. 
Phil. Mag. S. 5. Vol. 37. Pl. IX.

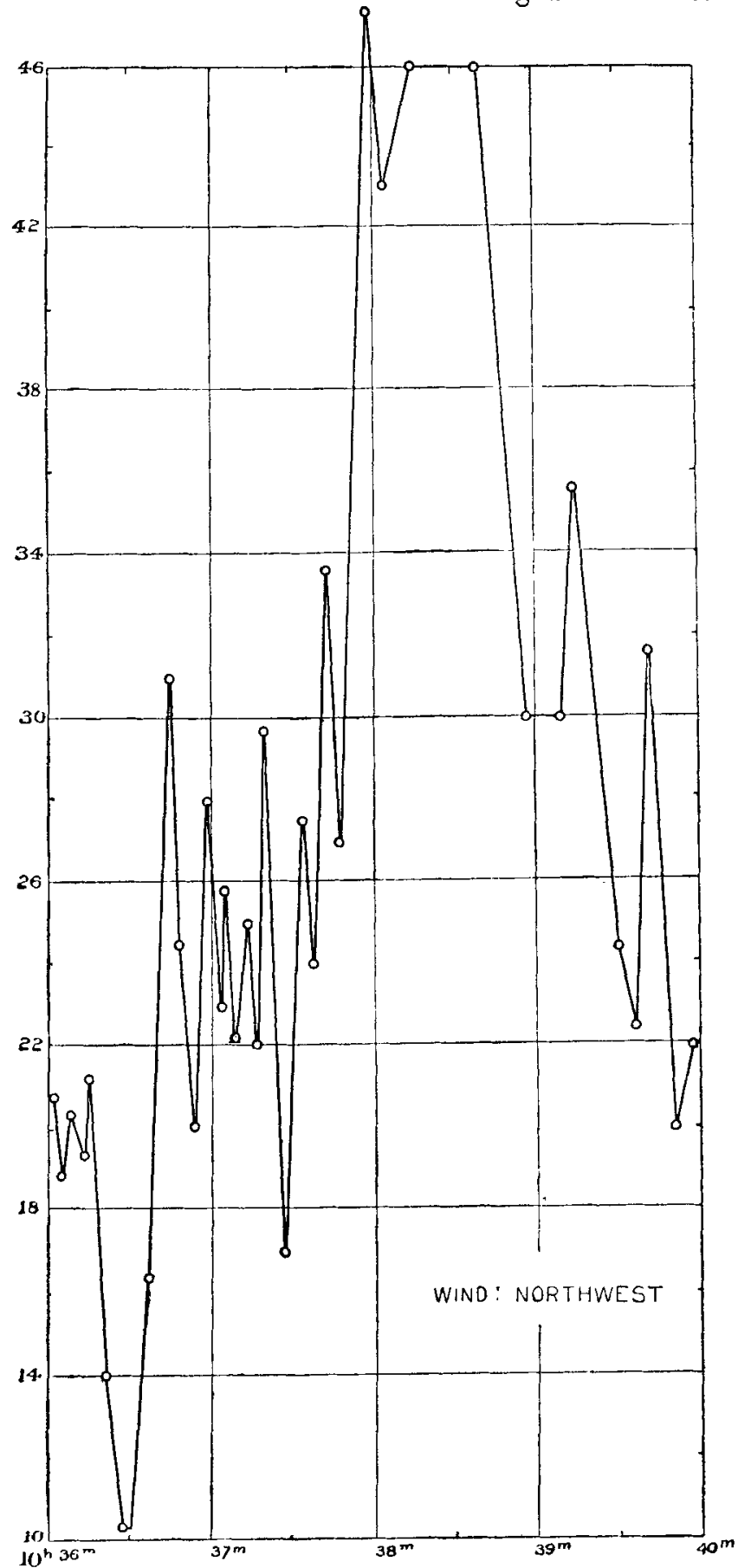

Wind velocities observed at Smithsonian Institution, February 20, 1893, with a Robinson anemometor (aluminum cups) registering every five revolutions.

Abscissae $=$ Time,

Ordinates $=$ Wind velocities in miles per hour. 
internal changes. Since the measured interval between two electric contacts is the datum for computing the velocity, an instantaneous stoppage, such as I accidentally saw, will appear on the record simply as a slowing of the wind, and such very significant facts as that just noted will be necessarily slurred over, even by the most sensitive apparatus of this kind.

However, the more frequent the contacts the more nearly an exact record of the fluctuations may be measured; and I have, as I have stated, provided that they should be made at every half revolution of the anemometer, that is, as a rule, several times a second *.

I now invite the reader's attention to the actual records of rapid changes that take place in the wind's velocity, selecting as an illustration the first $5 \frac{1}{2}$ minutes of the diagram plotted on Plate VII.

The heavy line through points $\mathrm{A}, \mathrm{B}$, and $\mathrm{C}$ represents the ordinary record of the wind's velocity as obtained from a standard Weather Bureau anemometer during the observations recording the passage of two miles of wind. The velocity, which was, at the beginning of the interval considered, nearly 23 miles an hour, fell during the course of the first mile to a little over 20 miles an hour. This is the ordinary anemometric record of the wind at such elevations as this ( 47 metres) above the earth's surface, where it is free from the immediate vicinity of disturbing irregularities, and where it is popularly supposed to move with occasional variation in direction, as the weather-cock indeed indicates, but with such nearly uniform movement that its rate of advance is, during any such brief time as two or three minutes, under ordinary circumstances, approximately uniform. This, then, may be called the "wind;" that is, the conventional "wind" of treatises upon aerodynamics, where its aspect as a practically continuous flow is

* Here we may note the error of the common assumption that the ordinary anemometer, however heavy, will, if frictionless, correctly measure the velocity of the wind, for the existence of "vis inertiæ" it is now seen, is not indifferent, but plays a most important part where the velocity suffers such great and frequent changes as we here see it does, and where the rate at which this inertia is overcome, and this velocity changed, is plainly a function of the density of the fluid, which density we also see reason to suppose itself varies incessantly, and with great rapidity. Though it is probable that no form of barometer in use does justice to the degree of change of this density, owing to this rapidity, we cannot, nevertheless, suppose it to exceed certain limits, and we may treat the present records, made with an anemometer of such exceptional lightness, as being comparatively unaffected by these changes in density, though they exist. 
alone considered. When, however, we turn to the record made with the specially light anemometer, at every second, of this same wind, we find an entirely different state of things. The wind, starting with the velocity of 23 miles an honr, at $12^{\mathrm{h}} 10^{\mathrm{m}} 18^{\mathrm{s}}$ rose within 10 seconds to a velocity of 33 miles an hour, and within 10 seconds more fell to its initial speed. It then arose within 30 seconds to a velocity of 36 miles an hour, and so on, with alternate risings and fallings, at one time actually stopping; and, as the reader may easily observe, passing through 18 notable maxima and as many notable minima, the average interval from a maximum to a minimum being a little over 10 seconds, and the average change of velocity in this time being about 10 miles an hour. In the lower left-hand corner of Plate VII. is given a conventional representation of these fluctuations in which this average period and amplitude is used as a type. The above are facts, the counterpart of which may be noted by any one adopting the means the writer has employed. It is hardly necessary to observe, that almost innumerable minor maxima and minima presented themselves, which the drawing cannot depict.

In order to ensure clearness of perception, the reader will bear in mind that the diagram does not represent the velocities which obtained coincidently, along the length of two miles of wind represented, nor the changes in velocity experienced by a single moving particle during the interval, but that it is a picture of the velocities which were in this wind at the successive instants of its passing the fixed anemometer ; which velocities, indeed, were probably nearly the same for a few seconds before and after registry, but which incessantly passed into, and were replaced by, others, in a continuous flow of change. But although the observations do not show the actual changes of velocity which any given particle experiences in any assigned interval, these fluctuations cannot be materially different in character from those which are observed at a fixed point, and are shown in the diagram. It may, perhaps, still further aid us in fixing our ideas, to consider two material particles as starting at the same time over this two-mile course: the one moving with the uniform velocity of 22.6 miles an hour (33 feet per second), which is the average velocity of the wind as observed for the interval between $12^{\mathrm{h}} 10^{\mathrm{m}} 18^{\mathrm{s}}$ and $12^{\mathrm{h}} 15^{\mathrm{m}} 45^{\mathrm{s}}$ on February 4 ; the other, during the same interval, having the continuously changing velocities actually indicated by the light anemometer, as shown on Plate VII. Their positions at any time may, if desired, be conveniently represented in a diagram where the abscissa of 
any point represents the elapsed time in seconds, and the ordinates show the distance, in feet, of the material particle from the starting-point. The path of the first particle will thus be represented by a straight line, while the path of the second particle will be an irregularly curved line, at one time above, and at another time below the mean straight line just described, but terminating in coincidence with it at the end of the interval. If, now, all the particles in two miles of wind were simultaneously accelerated and retarded in the same way as this second particle, that is, if the wind were an inelastic fluid and moved like a solid cylinder, the velocities recorded by the anemometer would be identical with those that obtained along the whole region specified. But the actual circumstance must evidently be far different from this, since the air is an elastic and nearly perfect fluid, subject to condensation and rarefaction. Hence the successive velocities of any given particle (which are in reality the resultant of incessant changes in all directions) must be conceived as evanescent, taking on something like the sequence recorded by these curves a very brief time before this air reached the anemometer, and losing it as soon after.

It has not been my purpose in this paper to enter upon any inquiry as to the cause of this non-homogeneity of the wind. The irregularities of the surface topography (including buildings and every other surface obstruction) are commonly adduced as a sufficient explanation of the chief irregularities of the surface wind; yet $I$ believe that at a considerable distance above the earth's surface (e.g. one mile) the wind may not even be approximately homogeneous, nor have an even flow ; for while, if we consider air as an absolutely elastic and frictionless fluid, any motion impressed upon it would be preserved for ever, and the actual irregularities of the wind would be the results of changes made at any past time, however remote; so long as we admit that the wind, without being absolutely elastic and frictionless, is nearly so, it seems to me that we may consider that the incessant alternations, which it here appears make the "wind," are due to past impulses and changes which are preserved in it, and which die away with very considerable slowness. If this be the case, it is less difficult to see how even in the upper air, and at every altitude, we might expect to find local variations, or pulsations, not unlike those which we certainly observe at minor altitudes above the ground *

* In this connexion, reference may be made to the notable investigations of Helmholtz on Atmospheric movements, Sitzungsberichte, Berlin, 1888 -1889 . 


\section{PART III.-Application.}

Of these irregular movements of the wind, which take place up, down, and on every side, and are accompanied of necessity by equally complex condensations and expansions, it will be observed that only a small portion, namely, those which occur in a narrow current whose direction is horizontal and sensibly linear, and whose width is only the diameter of the anemometer, can be noted by the instruments I have here described, and whose records alone are represented in the diagram. However complex the movement may appear as shown by the diagram, it is then far less so than the reality, and it is probable, indeed, that anything like a fairly complete graphical presentation of the case in impossible.

I think that on considering these striking curves (Plates V., VI., VII., VIII., and IX.), we shall not find it difficult to admit, at least as an abstract conception, that there is no necessary violation of the principle of the conservation of energy implied in the admission that a body wholly immersed in, and moving with such a wind, may derive from it a force which may be utilized in lifting the body, in a way in which a body immersed in the "wind" of our ordinary conception could not be lifted, and if we admit that the body may be lifted, it follows obviously that it may descend under the action of gravity from the elevated position, on a sloping path, to some distance in a direction opposed to that of the wind which lifted it, though it is not obvious what this distance is.

We may admit all this, because we now see (I repeat) that the apparent violation of law arises from a tacit assumption which we, in common with all others, may have made, that the wind is an approximately homogeneously moving body, because moving as a whole in one direction. It is, on the contrary, always as we see here, filled (even if we consider only movements in some one horizontal plane) with amazingly complex motions, some of which, if not in direct opposition to the main movement, are relatively so, that is are slower, while others are faster than this main movement, so that a portion is always opposed to it.

From this, then, we may now at least see that it is plainly within the capacity of an intelligence like that suggested by Maxwell, and which Lord Kelvin has called the "Sorting Demon," to pick out from the internal motions those whose direction is opposed to the main current, and to omit those which are not so, and thus, without the expenditure of energy, to construct a force which will act against the main current itself. 
But we may go materially further, and not only admit that it is not necessary to invoke here, as Maxwell has done in the case of thermodynamics, a being having power and rapidity of action far above ours, but that, in actual fact, a being of a lower order than ourselves, guided only by instinet, may so utilize these internal motions.

We might not, indeed, have conceived this possible, were it not that nature has already, to a large extent, exhibited it before our eyes in the soaring bird*, which sustains itself endlessly in the air with nearly motionless wings, for without this evidence of the possibility of an action which now ceases to approach the inconceivable, we are not likely, even if admitting its theoretical possibility, to have thought the mechanical solution of this problem possible.

But although to show how this physical miracle of nature is to be imitated, completely and in detail, may be found to transcend any power of analysis, I hope to show that this may be possible without invoking the asserted power of " aspiration" relative to curved surfaces, or the trend of upward currents, and even to indicate the probability that the mechanical solution of this problem may not be beyond human skill.

To this conclusion we are invited by the following consideration, among others.

* "When the condors in a flock are wheeling round and round any spot, their flight is beautiful. Except when rising from the ground, I do not recollect ever having seen one of these birds flap its wings. Near Lima I watched several for nearly half an hour without once taking off my eyes. They moved in large curves sweeping in circles, descending and ascending without once flapping. As they glided close over my head, I intently watched, from an oblique position, the outlines of the separate and terminal feathers of the wing; and if there had been the least vibratory movement these would have blended together, but they were seen distinct against the blue sky. The head and neck were moved frequently and apparently with force, and it appeared as if the extended wings formed the fulcrum on which the movements of the neck, body, and tail acted. If the bird wished to descend, the wings for a moment collapsed; and then, when again expanded, with an altered inclination, the momentum gained by the rapid descent seemed to urge the bird upwards, with the even and steady movement of a paper kite. In the case of any bird soaring, its motion must be sufficiently rapid so that the action of the inclined surface of its body on the atmosphere may counterbalance its gravity. The force to keep up the momentum of a body moving in a horizontal plane in that fluid (in which there is so little friction) cannot be great, and this force is all that is wanted. The movement of the neck and body of the condor, we must suppose, is sufficient for this. However this may be, it is truly wonderful and beautiful to see so great a bird, hour after hour, without any apparent exertion, wheeling and gliding over mountain and river:"-Darwin's Journal of the Various Countries Visited by H.M.S. ' Beagle,' pp. 223-224. 
We will presently examine the means of utilizing this potentiality of internal work in order to cause an inert body wholly unrestricted in its motion and wholly immersed in the current, to rise; but first let us consider such a body (a plane) whose movement is restricted in a horizontal direction, but which is free to move between frictionless vertical guides. Let it be inclined upward at a small angle towards a horizontal wind, so that only the vertical component of the pressure of the wind on the plane will affect its motion. If the velocity of the wind be sufficient, the vertical component of pressure will equal or exceed the weight of the plane, and in the latter case the plane will rise indefinitely.

Thus, to take a concrete example, if the plane be a rectangle whose length is six times its width, having an area of $2 \cdot 3$ square feet to the pound, and be inclined at an angle of $7^{\circ}$, and if the wind have a velocity of 36 feet per second, experiment shows that the upward pressure will exceed the weight of the plane, and the plane will rise, if between vertical nearly frictionless guides, at an increasing rate, until it has a velocity of 2.52 feet per second *, at which speed the weight and upward pressure are in equilibrium. Hence there are no unbalanced forces acting, and the plane will have attained a state of uniform motion.

For a wind that blows during 10 seconds, the plane will therefore rise about 25 feet. At the beginning of the motion, the inertia of the plane makes the rate of rise less than the uniform rate, but at the end of 10 seconds the inertia will cause the plane to ascend a short distance after the wind has ceased, so that the deficit at the beginning will be counterbalanced by the excess at the end of the assigned interval.

We have just been speaking of a material heavy plane permanently sustained in rertical guides, which are essential to its continuous ascent in a uniform wind, but such a plane will be lifted and sustained momentarily even if there be no vertical guides, or, in the case of a kite, even if there be no cord to retain it, the inertia of the body supplying for a brief period the office of the guides or of the cord. If suitably disposed, it will, as the writer has elsewhere shown, under the resistance to the horizontal wind, imposed only by its inertia, commence to move, not in the direction of the wind, but nearly vertically. Presently however, as we recognize, this inertia must be overcome, and as the inclined plane takes up more and more the motion of the wind, the lifting effect must grow less and less (that is to say, if the wind

* See " Experiments in Aerodynamics," by S. P. Langley, "Smithsonian Contribution to Knowledge,' 1891. 
be the approximately homogeneous current it is commonly treated as being), and finally ceasing altogether, the plane must ultimately fall. If, however, a counter-current is supposed to meet this inclined plane, before the effect of its inertia is exhausted, and consequently before it ceases to rise, we have only to suppose the plane to be rotated through $180^{\circ}$ about a vertical axis, without any other call for the expenditure of energy, to see that it will now be lifted still higher, owing to the fact that its inertia now reappears as an active factor. The annexed sketch (fig. 1) shows a typical representation of what might be supposed to happen with a model inclined plane freely suspended in the air, and endowed with the power

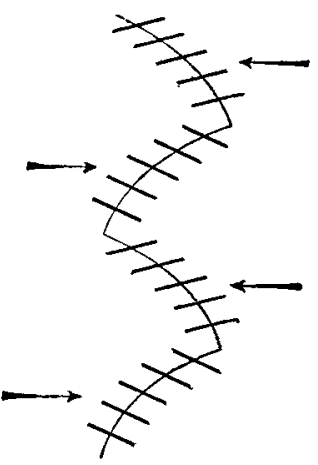

Fig.1. of rotating about a vertical axis so as to change the aspect of its constant inclination, which need involve no (theoretical) expenditure of energy, even although the plane possess inertia. We see that this plate would rise indefinitely by the action of the wind in alternate directions.

The disposition of the wind which is here supposed to cause the plane to rise appears at first sight an impossible one, but we shall next make the important observation that it becomes virtually possible by a method which we shall now point out, and which leads to a practicable one which we may actually employ.

Figure 2 shows the wind blowing in one constant direction, but alternately at two widely varying velocities, or rather (in the extreme case supposed in illustration) where one of the velocities is negligibly small, and where successive pulsations in the same direction are separated by intervals of calm.

A frequent alternation of velocities, united with constancy of absolute direction, has previously been shown here to be the ordinary condition of the wind's motion ; but attention is now particularly called to the fact that while these unequal velocities may be in the same direction as regards the surface of the earth, yet as regards the mean motion of the wind they are in opposite directions, and will produce on a plane, whose inertia enables it to sustain a sensibly uniform motion with the mean velocity of this variable wind, the same lifting effect as if these same alternating winds were in absolutely opposed directions, provided that the constant inclination of 
the plane alternates in its aspect to correspond with the changes in the wind.

It may aid in clearness of conception, if we imagine a set of fixed coordinates $\mathrm{X} Y \mathrm{Z}$ passing through $\mathrm{O}$, and a set of movable coordinates $x y z$, moving with the velocity and the direction of the mean wind. If the moving body is referred to these first only, it is evidently subject to pulsations which take place in the same directions on the axis of $\mathrm{X}$, but it must be also evident that if referred to the second or movable coordinates, these same pulsations may be, and are, in opposite directions. This, then, is the case we have just considered, and if we suppose the plane to change the aspect * of its (constant) inclination as the direction of the pulsations changes, it is evident that there must be a gain in altitude with every pulsation, while the

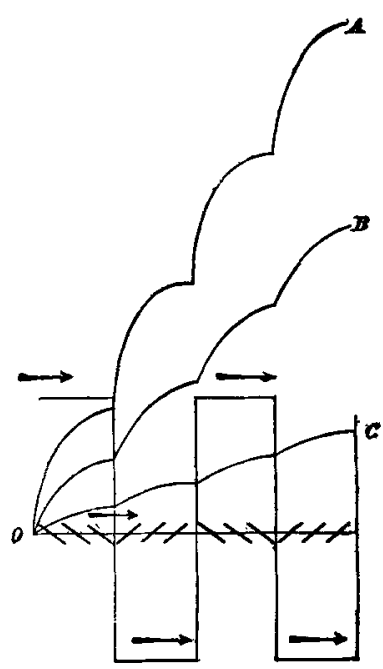

Itg. 2. plane advances horizontally with the velocity of the mean wind.

During the period of maximum wind velocity, when the wind is moving faster than the plane, the rear edge of the latter must be elevated. During the period of minimum velocity, when the plane, owing to its inertia, is moving faster than the wind, the front edge of the plane must be elevated. Thus the vertical component of the wind pressure, as it strikes the oblique plane, tends in both cases to give it a vertical upward thrust. So long as this thrust is in excess of the weight to be lifted, the plane will rise. The rate of rise will be greatest at the beginning of each period, when the relative velocity is greatest, and will diminish as the resistance produces "drift;" i. e. diminishes relative velocity. The curved line O B in the vignette represents a typical path of the plane under these conditions.

It follows from the diagram (fig. 1) that, other things being equal, the more frequent the wind's pulsations, the greater will be the rise of the plane; for since during each period of

* We do not for the moment consider how this change of aspect is to be mechanically effected; we only at present call attention to the fact that it involves, in theory, no expenditure of energy.

Plil. Mag. S. 5. Vol. 37. No. 228. May 1894. $2 \mathrm{H}$ 
steady wind the rate of rise diminishes, the more rapid the pulsations, the nearer the mean rate of rise will be to the initial rate. The requisite frequency of pulsations is also related to the inertia of the plane, as the less the inertia, the more frequent must be the pulsations in order that the plane shall not lose its relative velocity.

It is obvious that there is a limit or weight which cannot be exceeded, if the body is to be sustained by any such fluctuations of velocity as can be actually experienced. Above this limit of weight the body will sink. Below this limit the lighter the body is the higher it will be carried, but with increasing variability of speed. That body, then, which has the greatest weight per unit of surface will soar with the greatest steadiness, if it soar at all, not on account of this weight per se, but because the weight is an index of its inertia.

The reader who will compare the results of experiments made with any artificial flying models, like those of Penand, with the weights of the soaring birds as given in the tables by M. Mouillard, or other authentic sources, cannot fail to be struck with the great weight in proportion to wing-surface which nature has given to the soaring bird, compared with any which man has yet been able to imitate in his models.

This fact of the weight of the soaring bird in proportion to its area has been again and again noted, and it has been frequently remarked that without weight the bird could not soar, by writers who felt that they could very safely make such a paradoxical statement, in view of the evidence nature everywhere gave that this weight was indeed in some way necessary to rising. But these writers have not shown, so far as I remember, how this necessity arises, and this is what I now endeavour to point out*.

It has not here been shown what limit of weight is imposed to the power of an ordinary wind to elevate and sustain, but it seems to me, and I hope that it may seem to the reader, that the evidence that there is some weight which the action of the wind is sufficient to permanently sustain under these conditions in a free body, has a demonstrative character, although no quantitative formula is offered at this stage of the investigation. It is obvious that, if this weight is sus-

* It is perhaps not superfuous to recall here that, according to the researches of Rankine, Froude, and others, a body moulded in wave-line curves would, if frictionless, continue to move indefinitely against an opposed wind, in virtue of inertia and once acquired velocity, and also to recall bow very small the effect of fluid friction in the air has been shown to be (by the writer in a previous investigation). 
tainable at any height, gravity may be utilized to cause the body (which we suppose to be a material plane) to descend on an inclined course, to some distance, even against the wind.

I desire, in this connexion, to remark that the preceding experiments and deductions, showing that a material free plane *, possessing sufficient inertia, may in theory rise indefinitely by the action of an ordinary wind, without the expenditure of work from any internal source (as well as those statements which follow), when these explanations are once made, have a character of obviousness, which is due to the simplicity of the enunciation, but not, I think, to the familiarity of the explanation, for though attention is beginning to be paid by meteorologists to the rapidity of these wind fluctuations, I am not aware that their effects have been so exhibited, or, especially, that they have been presented in this connexion, or that the conclusions which follow have been drawn from them.

We have here seen, then, how pulsations of sufficient amplitude and frequency, of the kind which present themselves in nature, may, in theory, furnish energy not only sufficient to sustain, but actually to elevate, a heavy body moving in and with the wind at its mean rate.

It is easy now to pass to the practical case which has been already referred to, and which is exemplified in nature, namely, that in which the body (e.g. the bird soaring on rigid wings, but having power to change its inclination) uses the elevation thus gained to move against the wind, without expending any sensible amount of its own energy. Here the upward motion is designedly arrested at any convenient stage, e.g. at each alternate pulsation of the wind, and the height attained is utilized so that the action of gravity may carry the body by its descent in a curvilinear path (if necessary) against the wind. It has just been pointed out that if some height has been attained, the theoretical possibility of some advance against the wind in so falling hardly needs demonstration, though it may not unnaturally be supposed that the relative advance so gained must be insignificant, compared with the distance travelled by the mean wind while

* I use the word "plane," but include in the statement all suitable modifications of a curved surface.

I desire to recall attention to the paragraph in "Experiments in Aerodynamics," in which I caution the reader against supposing that by investigating plane surfaces I imply that they are the best form of surface for flight; and I repeat here that, as a matter of fact, I do not believe them to be so. I have selected the plane simply as the best form for preliminary experiment. 
the body was being elevated, so that on the whole the body is carried by the wind farther than it advances against it.

This, however, probably need not be in fact the case, there being, as it appears to me from experiment and from deduction, every reason to believe that under suitable conditions the advance may be greater than the recession, or that the body falling under the action of gravity along a suitable path may return against the wind, not only from $Z$ to $O$, the point of departure, but farther, as is here shown.

I repeat, however, that I am not at the moment undertaking to demonstrate how the action is mechanically realizable in actual practice, but only that it is possible. It is for this purpose, and to understand more exactly that it can be effected, not only by the process indicated in the second illustration (fig. 2) but by another and probably more useful one (and nature has still others at command), that I have considered another treatment of the same conditions, of windpulsations always moving in the same horizontal direction, but for brief periods, interrupted by equal intervals of calm. In this third illustration (fig. 3) we suppose the body to use the height gained in each pulsation, to enable it to descend after each such pulsation and advance against the direction of the wind.

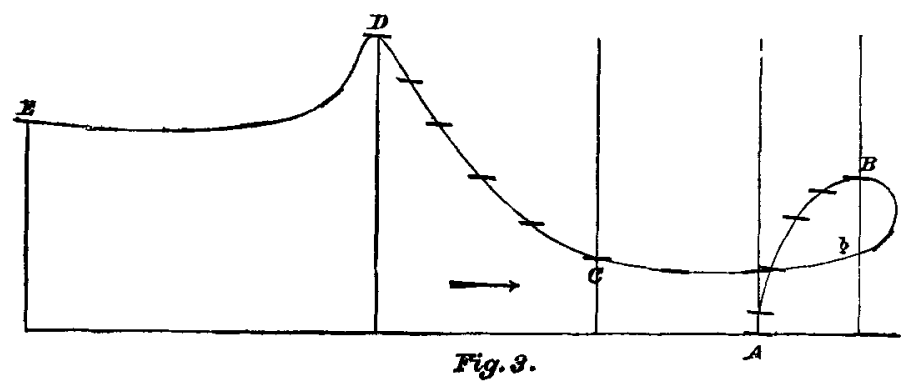

The portion $\mathrm{AB}$ of the curve represents the path of the plane surface from a state of rest at $A$, where it has a small upward inclination toward the wind. If a horizontal wind blow upon it in the direction of the arrow, the first movement of the plane will not be in the direction of the wind, but, as is abundantly demonstrated by the writer in "Experiments in Aerodynamics," it will rise in a nearly vertical direction, if the angle be small. The wind, continuing to blow in the same direction, at the end of a certain time, the plane, which has risen (owing to its inertia, and in spite of its weight) to the successive positions shown, is taking up more and more of the 
horizontal velocity of the wind, and consequently opposing less resistance to it, and therefore moving more and more laterally, and rising less and less, at every successive instant.

If the wind continued indefinitely, the plane would ultimately take up its velocity, and finally, of course, fall, when this inertia ceased to oppose resistance to the wind's advance. I have supposed, however, the wind pulsation to cease at the end of a certain brief period, and, to fix our ideas, let us suppose this period to be five seconds. At this moment the period of calm begins, and now let the plane, which is supposed to have reached the point $B$, change its inclination about a horizontal axis to that shown in the diagram, falling at first nearly vertically, with its edge on the line of its descent, so as to acquire speed, and this speed acquired, by constantly changing its angle, glide down the curve $\mathrm{B} b \mathrm{C}$, so that the plane shall be tangential to it at every point of its descending advance. At the end of five seconds of calm it has reached the position $\mathrm{C}$, near the lowest point of its descent, which there is no contradiction to known mechanical laws in supposing may be higher than $\mathrm{A}$, and which in fact, according to the most accurate data the writer can gather, $i s$ higher, in the case of the above period, and in the case of such an actual plane as has been experimented upon by him.

Now, having reached $\mathrm{C}$, at the end of the five seconds' calm, if the wind blow in the same direction and velocity as before, it will again elevate the plane on the latter's presenting the proper angle, but this time under more favourable circumstances, for at this time the plane is already in motion in a direction opposed to that of the wind, and is already higher than it was in its original position A. Its course, therefore, will be nearly that along the curve $C D$, during all which time it maintains the original angle $a$ or one very slightly less. Arrived at D, and at the instant when the calm begins, it falls, with varying inclination, to the lowest position $\mathbf{E}$ (which may be higher than ()), which it attains at the end of the five seconds of calm, then rises again (still nearly at the angle $a$ ) to a higher position, and so on ; the alternation of directions of motion, at the end of each pulsation, growing less and less sharp, and the path finally taking the character of a sinuous curve. We have here assumed that the plane goes against the wind and rises at the same time, in order to illustrate that this is possible, though either alternative may be employed, and the plane, in theory at least, may maintain on the whole a rapid and nearly horizontal, or a slow and nearly vertical course, or anything between.

It is not meant, either, that the alternations which would be 
observed in nature are as sharp as those here represented, which are intentionally exaggerated, while in all which has just preceded, by an equally intentional exaggeration of the normal action, the wind-pulsations have been supposed to alternate with absolute calm. This being understood, it is scarcely necessary to point out that if the calm is not absolute, but if there are simply frequent successive winds or pulsations of wind of considerably differing velocity (such as the anemometer observations show are realized in nature), the same general effect will obtain*, though we are not entitled to assume from any demonstration thus far given that the total advance will be necessarily greater than that of the whole distance the mean wind has travelled. It may also be observed that the actual actions of the soaring bird may be, and doubtless are, more complex in detail than those of this diagram, while yet in their entirety depending on the principles it sets forth.

The theoretical possibility at least will now, it is hoped, be granted, not only of the body's rising indefinitely, or of its descending in the interval of calm to a higher level $\mathrm{C}$ than it rose from at $A$, but of its advancing against the calm or light wind through a distance $\mathrm{BC}$, greater than that of $\mathrm{AB}$, and so on. The writer, however, repeats that he has reason to suppose, from the data obtained by him, that this is not only a theoretical possibility, but a mechanical probability under the conditions stated, although he does not here offer a quantitative demonstration of the fact, other than by pointing to the movements of the soaring bird and inviting their reconsideration in the light of the preceding statements.

The bird, by some tactile sensibility to the pressure and direction of the air, is able, in nautical phrase, to "see the wind $" \dagger$ and to time its movements so that, without any reference to its height from the ground, it reaches the lowest portion of its descent near the end of the more rapid windpulsation; but the writer believes that to canse these adaptive

* The rotation of the body about a vertical axis so as to change the aspect of the inclination, as in the first figure, may be illustrated by the well-known hakit of many soaring birds, of moring in small closed curves or spirals, but it may also be observed, in view of the fact that even in intervals of relative calm during which the body descends, there is always some wind,- that in making the descents, if the body, animate or inanimate, maintain its direct advance, this wind tends to strike on the upper side of the plane or pinion. Mr. G. E. Curtis offers the suggestion that the soaring bird aroids such a position when possible, and therefore turns at right angles to, or with, the wind, and that this may be an additional reason for its well-linown habit of moving in spirals.

+ Mouillard. 
changes in an otherwise inert body, with what might almost be called instinctive readiness and rapidity, does not really demand intelligence or even instinct, but that the future aerodrome may be furnished with a substitute for instinct, in what may perhaps allowably be called a mechanical brain, which yet need not, in his opinion, be intricate in its character. His reasons for this statement, which is not made lightly, must, however, be reserved for another time.

It is hardly necessary to point out that the nearly inert body in question may also be a human body, guided both by instinct and intelligence, and that there may thus be a sense in which human flight may be possible, although flight depending wholly upon the action of human muscles be for ever impossible.

Let me resume the leading points of the present memoir in the statement that it has been shown :-

(1) That the wind is not even an approximately uniform moving mass of air, but consists of a succession of very brief pulsations of varying amplitude, and that, relatively to the mean movement of the wind, these are of varying direction.

(2) That it is pointed out that hence there is a potentiality of "internal work" in the wind, and probably of a very great amount.

(3) That it involves no contradiction of known principles to declare that an inclined plane, or suitably curved surface, heavier than the air, freely immersed in, and moving with the velocity of the mean wind, can, if the wind-pulsations here described are of sufficient amplitude and frequency, be sustained or even raised indefinitely without expenditure of internal energy, other than that which is involved in changing the aspect of its inclination at each pulsation.

(4) That since (A) such a surface, having also power to change its inclination, must gain energy through falling during the slower, and expend energy by rising during the higher, velocities; and that $(\mathrm{B})$ since it has been shown that there is no contradiction of known mechanical laws in assuming that the surface may be sustained or may continue to rise indefinitely, the mechanical possibility of some advance against the direction of the wind follows immediately from this capacity of rising. It is further seen that it is at least possible that this advance against the wind may not only be attained relatively to the position of a body moving with the speed of the mean wind, but absolutely, and with reference to a fixed point in space.

(5) The statement is made that this is not only mechanically possible, but that, in the writer's opinion, it is realizable in practice. 
Finally, these observations and deductions have, it seems to me, an important practical application not only as regards a living creature like the soaring bird but still more as regards a mechanically constructed body, whose specific gravity may probably be many hundred or even many thousand times that of the atmosphere. We may suppose such a body to be supplied with fuel and engines, which would be indispensable to sustain it in a calm, and yet which we now see might be ordinarily left entirely inactive, so that the body could supposably remain in the air and even maintain its motion in any direction without expending its energy, except as regards the act of changing the inclination or aspect which it presents to the wind, while the wind blew.

The final application of these principles to the art of aerodromics seems then to be, that while it is not likely that the perfected aerodrome will ever be able to dispense altogether with the ability to rely at intervals on some internal source of power, it will not be indispensable that this aerodrome of the future shall, in order to go any distance-even to circumnavigate the globe without alighting,-need to carry a weight of fuel which would enable it to perform this journey under conditions analogous to those of a steamship, but that the fuel and weight need only be such as to enable it to take care of itself in exceptional moments of calm.

Smithsonian Institution,

Washington, D. C., August 1893.

\section{A new Electrical Theorem.}

$B y$ Thomas H. Blakesley, M.A.*

THE very short paper which I shall read to the Society contains the account of a Theorem which, though admitting of easy proof, appears, so far as my inquiries have gone, to have hitherto escaped notice.

In order to state the matter briefly, it will be well to adopt the following definition :-

If in any system of conductors, however reticulated, two or more modes of disposition of sources of electromotive force produce in every part of the network the same current, such systems of disposition are called equivalent systems. Then the theorem is as follows:- In any system of conductors, possessing seats of electromotive force at any number of points, if any of these sources be supposed to move continuously along the various bars of the conducting system,

* Communicated by the Physical Society : read February 23, 1894. 